\title{
Pseudomicetoma dermatofítico em felinos
}

\author{
Dermatophytic pseudomycetoma in felines
}

Raimundo Alberto Tostes ${ }^{1}$ Rogério Giuffrida ${ }^{2}$

\section{- RELATO DE CASO -}

\section{RESUMO}

As infecções fúngicas dermatofiticas profundas, conhecidas como pseudomicetomas, são raras em animais domésticos. O pseudomicetoma dermatofitico tem sido relatado nos gatos, cães, eqüinos, assim como no homem. Na ampla maioria dos casos, o agente isolado é Microsporum canis. No presente artigo, relatam-se dois casos de pseudomicetoma dermatofitico felino, nos quais o fungo isolado foi M. canis. As lesões caracterizavam-se por nódulos variando de 1,0 a $1,5 \mathrm{~cm}$ de diâmetro, friáveis e com exsudação purulenta em um dos casos. Histologicamente, as lesões eram características de dermatite granulomatosa profunda, com predominio de macrófagos, células epitelióides e a discreta presença de plasmócitos, eosinófilos e um denso agregado de hifas em meio a uma marcante reação Splendori-Hoeppli eosinofilica.

Palavras-chave: pseudomicetoma;dermatofitose;Microsporum canis.

\section{ABSTRACT}

Deep dermatophytic fungal infections, known as pseudomycetomas, are rare in domestic animals. Dermatophytic pseudomycetoma has been described in cats, dogs, equine and men. Most cases, M. canis is the fungi isolated. In the present article we report two cases of dermatophytic pseudomycetoma in cats. Lesions were characterized by nodules ranged from 1.0 to $1.5 \mathrm{~cm}$ in diameter, friable and with purulent exudation in one case. Histologically, lesions are presented by deep granulomatous dermatitis, predominating macrophages, epithelioid cells and a discrete number of plasma cells, eosinophils, and dense hyphae aggregate surrounded by marked eosinophilic Splendori-Hoeppli reaction.

Key words: pseudomycetoma dermatophytosis;Microsporum canis.

\section{INTRODUÇÃO}

As dermatofitoses ou dermatofitias acometem o homem e diversas espécies domésticas, tendo como agentes etiológicos uma grande variedade de fungos denominados coletivamente como dermatófitos (MORAES et al., 2001). Estes fungos, reunidos nos gêneros Microsporum, Trichophyton e Epidermophyton são ceratinofílicos e assemelhados morfologicamente entre si (LACAZ et al., 1998). Os dermatófitos são a maior e mais prevalente causa de micose em animais e no homem (RINALDI et al., 1983). Os dermatófitos zoofílicos, como M. canis por exemplo, têm nos cães e gatos seus mais importantes portadores, espécies estas consideradas como seus hospedeiros naturais aos quais estes dermatófitos estão altamente adaptados (DVORÁK \& OTCENÁSEK, 1982).

\footnotetext{
${ }^{1}$ Professor Assistente Anatomia Patológica, Hospital Veterinário, Universidade do Oeste Paulista, Campus II. Rod. Raposo Tavares km 572. 19001-970, Presidente Prudente, SP. E-mail: ratostes@uol.com.br. Autor para correspondência.

${ }^{2}$ Professor Assistente Moléstias Infecciosas, Hospital Veterinário, Universidade do Oeste Paulista.
} 
A nomenclatura de infecções dermatofíticas profundas é controversa. AJELLO et al. (1980) consideram que as lesões causadas pelos dermatófitos Microsporum spp e Trichophyton spp não exibem grãos ou drusas verdadeiras, possuindo um micélio escasso e sem entrelaçamento compacto, como nos grãos eumicóticos. AJELLO et al. (1980) e RINALDI et al. (1983) postulam que os micetomas eumicóticos verdadeiros, causados por fungos não-pigmentados ou por fungos dematiáceos, devem incluir a seguinte tríade: a tumefação do tecido envolvido, o aspecto de micro-colônias do agente no tecido infectado que correspondem aos grãos ou grânulos e a formação de drenos fistulosos para o exterior da lesão. O pseudomicetoma dermatofítico tem sido referido em felinos (TUTTLE \& CHANDLER, 1983; MILLER \& GOLDSCHMIDT, 1986; YAGER et al., 1986; BLACK et al., 2001), homens (RINALDI et al., 1983; CHEN et al., 1993; MORAES et al., 2001) e cães (ABRAMO et al., 2001) e trata-se de uma rara infecção subcutânea na qual a reação granulomatosa envolve as hifas dermatofiticas (ABRAMO et al., 2001). Na ampla maioria dos casos, o agente isolado é $\boldsymbol{M}$. canis. TUTTLE \& CHANDLER (1983) citam que a prevalência de $\boldsymbol{M}$. canis em gatos portadores clinicamente normais varia de 5,9 a $91 \%$ e que somente $\boldsymbol{M}$. canis é responsável por $90 \%$ das infecções dermatofíticas em gatos. Na Inglaterra, QUAIFE \& WOMAR (1982) determinaram que até 35\% de gatos de pêlo longo, assintomáticos em exposições, estavam infectados por M. canis. Entretanto, há significativas variações na freqüência e distribuição dos dermatófitos em pequenos animais.

A patogenia desta infecção micótica profunda ainda não está bem esclarecida. AJELLO et al. (1980) e CHEN et al. (1993) sustentam que a patogenia do pseudomicetoma é similar ao do chamado granuloma de Majocchi, condição na qual as hifas invadem um folículo piloso, penetram no tecido adjacente, agregam-se e induzem uma reação imunológica marcante. CARETTA et al. (1989) sugerem que a relação simbiótica entre dermatófitos zoofílicos e pulgas também pode desempenhar um papel significativo na disseminação da dermatofitose e lesões decorrentes. MORIELLO \& DeBOER (1991) citam que a infecção por dermatófitos também pode estar condicionada a alterações na microbiota bacteriana e fúngica saprófitas do hospedeiro e às mudanças nas propriedades dos ácidos graxos de cadeia curta, de propriedade fungicida, produzidas pelas glândulas sebáceas da pele. TUTTLE \& CHANDLER (1983) acreditam que o pseudomicetoma pode aparecer como seqüela de lesões cutâneas pré-existentes. YAGER et al. (1986) creditam parte do desenvolvimento do pseudomicetoma à imunossupressão decorrente de processos infecciosos ou terapia. Contudo, apesar da discordância quanto à patogenia, é plenamente reconhecida a predisposição da raça Persa (MILLER \& GOLDSCHMIDT, 1986; YAGER et al., 1986; ABRAMO et al., 2001; BLACK et al., 2001).

No presente artigo, relatam-se dois casos distintos de pseudomicetoma dermatofítico causados por M. canis.

\section{RELATO DOS CASOS}

\section{Caso 1.}

O primeiro animal tratava-se de um gato sem raça definida, macho, de 5 anos de idade. Segundo a descrição do proprietário, o animal apresentou inicialmente uma nodulação friável na base da cauda, medindo $1,5 \mathrm{~cm}$ de diâmetro, sem precisar o período em que surgiu a lesão. No momento do exame clínico, o animal apresentava-se apático e em estado nutricional hipotrófico. Foram colhidas amostras de sangue para realização de hemograma e posteriormente a lesão foi extirpada cirurgicamente e encaminhada para análise histológica, bacteriológica e micológica. Após a primeira consulta, surgiram outras três nodulações de $1,0 \mathrm{~cm}$ de diâmetro, distribuídas ao longo da região dorso lombar e base da cauda. Embora se tenha realizado antibioticoterapia com enrofloxacina na dose de $2,5 \mathrm{mg} / \mathrm{kg}$ ao dia durante uma semana e terapia antifúngica com cetoconazol na dose de $30 \mathrm{mg} / \mathrm{kg} / \mathrm{dia}$ preconizado para 30 dias, o animal veio a óbito duas semanas após o diagnóstico ser estabelecido.

\section{Caso 2.}

O segundo animal, um gato persa, macho, de 8 anos de idade, exibia três nódulos pelo corpo com as dimensões variando de 1,0 a $1,5 \mathrm{~cm}$ de diâmetro. Todos os nódulos estavam situados no dorso do animal, dois na região cervical dorsal e o terceiro na região dorso-lombar. As lesões foram extirpadas cirurgicamente e encaminhadas para exame histológico. Fragmentos das massas também foram encaminhados para exame bacteriológico e micológico. O exame micológico apresentou resultado negativo. No exame bacteriológico foi isolado Staphylococcus sp. Todas as lesões eram pruriginosas e exibiam exsudação purulenta. Poucas semanas após a exérese das massas, houve recidiva das nodulações. Em razão da suspeita de dermatite fúngica, foi realizada uma biópsia incisional por bisturi do seio da lesão maior exclusivamente para realização de cultura fúngica.

\section{RESULTADOS E DISCUSSÃO}

Em ambos os casos, houve o isolamento de M. canis a partir da exérese dos nódulos. O diagnóstico microbiológico foi firmado a partir do isolamento de 
colônias puras de M. canis em Ágar-Saboraud-dextrose e Ágar Mycosel.

$\mathrm{Na}$ necropsia do caso 1, observou-se no local dos nódulos a presença de extensas áreas de necrose envolvendo pele, tecido subcutâneo e musculatura. Os linfonodos cervicais superficiais e profundos, apresentavam-se reativos, o que foi caraterizado histologicamente como disseminação da infecção a partir do nódulo cervical. Exceto para os linfonodos regionais, não foi caracterizada macro e microscopicamente a visceralização da infecção.

Os achados histopatológicos dos nódulos cutâneos em ambos os casos obedeceram praticamente ao mesmo padrão: ao HE, observava-se um denso agregado de hifas septadas, de formato irregular, muitas com intervalos cilíndricos regulares semelhantes a esporos. O centro das lesões exibia marcante reação Splendori-Hoeppli eosinofílica P.A.S.-positiva. A infiltração inflamatória era predominantemente mononuclear com marcante presença de macrófagos e células epitelióides e com a presença discreta de plasmócios e eosinófilos. As estruturas fúngicas foram fortemente impregnadas pela Prata Metenamina de Gomori. Perifericamente, as lesões exibiam grau acentuado de fibrose. Os achados histológicos são concordantes com aqueles observados por MILLER \& GOLDSCHMIDT (1986), YAGER et al. (1986), ABRAMO et al. (2001) e BLACK et al. (2001). O padrão de lesão que permite classificar estes dois casos como pseudomicetomas é configurado pela ausência da formação de grânulos, a presença da reação de Splendori-Hoeppli, a estrutura filamentosa compacta das hifas e a ausência de matriz cimentante, o que está de acordo com o postulado de AJELLO et al. (1980) e RINALDI et al. (1983).

O tratamento com cetoconazol no caso 2 na dose de $30 \mathrm{mg} / \mathrm{kg} / \mathrm{dia}$, associado à antibioticoterapia com cefalexina na dose de $20 \mathrm{mg} / \mathrm{kg} / \mathrm{BID}$ durante 7 dias, promoveu uma significativa redução no tamanho das lesões. Tendo uma boa penetração sistêmica, o cetoconazol pode ser a droga de eleição para estes casos. PUCCINI et al. (1992) observaram uma sensibilidade de $\boldsymbol{M}$. canis ao cetoconazol em 50,7\% das amostras cultivadas. Foi sugerido ao proprietário que as lesões remanescentes fossem extirpadas cirurgicamente e mantida a terapia com cetoconazol a fim evitar a recidiva das lesões. Neste caso, a infecção fúngica foi agravada pela infecção bacteriana secundária. $\mathrm{O}$ desconforto provocado pelo prurido induz o animal a automutilação, o que prejudica sobremaneira na remissão do processo. É altamente relevante, nos dois casos, o caráter progressivo e recidivante das lesões. Embora não tenha sido evidenciado nenhum quadro infeccioso imunossupressivo, é provável que haja alguma correlação entre a evolução dos pseudomicetomas e a resposta imune, no que concordam YAGER et al. (1986) e MORAES et al. (2001).

\section{REFERÊNCIAS BIBLIOGRÁFICAS}

ABRAMO, F.; VERCELLI, A.; MACIANTI, F. Two cases of dermatophytic pseudomycetoma in the dog: an immunohistochemical study. Vet Dermatol, v.12, n.4, p.203207, 2001

AJELLO, A.; KAPLAN, W.; CHANDLER, F.W. Dermatophyte mycetoma: fact or fiction? Proceedings of $5^{\text {th }}$ International Conference on Mycoses Pan Am Health Org Sci Pub, v.396, p.135-140, 1980.

BLACK, S.S. et al. Intra-abdominal dermatophytic pseudomycetoma in a persian cat. J Vet Intern Med, v.15, n.3, p.245-248, 2001

CARETTA, G.; MANCIANTI, F.; AJELLO, L. Dermatophytes and keratinophilic fungi in cats and dogs. Mycoses v.32, n.8, p.620-626, 1989.

CHEN, A.W.J. et al. Dermatophyte pseudomycetoma: a case report. Br J Dermatol, v.129, n.6, p.729-732, 1993.

DVORÁK, J.; OTCENÁSEK, M. Natural relationships of dermatophytes to the milieu of their existence. A review. Mycoses, v.25, n.4, p.197-209, 1982.

LACAZ, C.S. et al. Identificação dos fungos. In : Guia para identificação: fungos, actinomicetos, algas de interesse médico. São Paulo : Sarvier-FAPESP, 1998. p. 65-66.

MILLER Jr., W.H.; GOLDSCHMIDT, M.H. Mycetomas in the cat caused by a dermatophyte: a case report. J Am Anim Hosp Assoc, v.22, n.3/4, p.255-260, 1986.

MORAES, M.A.P. et al. Pseudomicetoma dermatofítico: relato de um caso devido a Trichophyton tonsurans. Rev Soc Bras Méd Trop, v.34, n.3, p.291-294, 2001.

MORIELLO, K.A.; DeBOER, D.J. Fungal flora of the haircoat of cats with and without dermatophytosis. J Med Vet Mycol, v.29, n.5, p.285-292, 1991.

PUCCINI, S. et al. In vitro suscetibility to antimycotics of Microsporum canis isolates from cats. J Am Vet Med Assoc, v.201, n.9, p.1375-1377, 1992.

QUAIFE, R.A.; WOMAR, S.M. Microsporum canis isolations from show cats. Vet Rec, v.110, n.14, p.333-334, 1982.

RINALDI, M.G. et al. Mycetoma or pseudomycetoma. A distinctive mycosis caused by dermatophytes. Mycopathol, v.81, n.1, p.41-48, 1983.

TUTTlE, P.A.; CHANDLER, F.W. Deep dermatophytosis in a cat. J Am Vet Med Assoc, v.183, n.10, p.1106-1108, 1983.

YAGER, J.A. et al. Mycetoma-like granuloma in a cat caused by Microsporum canis. J Comp Pathol., v.96, n.2, p.171-176, 1986. 